\title{
Bronchial thermoplasty and the role of airway smooth muscle: are we on the right direction?
}

\author{
This article was published in the following Dove Press journal: \\ Therapeutics and Clinical Risk Management \\ 19 September 2017 \\ Number of times this article has been viewed
}

\author{
Francesco Menzella' \\ Mirco Lusuardi ${ }^{2}$ \\ Carla Galeone' \\ Nicola Facciolongo' \\ 'Department of Medical Specialties, \\ Pneumology Unit, IRCCS - Arcispedale \\ Santa Maria Nuova, Reggio Emilia, \\ ${ }^{2}$ Unit of Respiratory Rehabilitation, \\ AUSL Reggio Emilia, S Sebastiano \\ Hospital, Correggio, Italy
}

\begin{abstract}
Asthma is characterized by inflammation of the airways that includes eosinophils, basal membrane thickening, epithelial sloughing, vascular changes, smooth muscle hypertrophy and hyperplasia, and mucous gland hyperplasia. Recently, there have been studies on the role of hypersensitivity and inflammation in asthma, but the role of bronchial smooth muscle remains unclear. Bronchial thermoplasty is an endoscopic procedure that is approved by the US Food and Drug Administration (FDA) for the treatment of severe refractory asthma, based on the local delivery of radio frequency at $65^{\circ} \mathrm{C}$ to the airways, with the aim of controlling bronchospasm through a reduction of airway smooth muscle (ASM). Several recent studies have shown significant improvement in clinical outcomes of bronchial thermoplasty for asthma, including symptom control, reduction in exacerbation and hospitalization rates, improved quality of life, and reduction in number of working days or school days lost due to asthma. Data from these recent studies have shown reduction in ASM following bronchial thermoplasty and changes in inflammation patterns. It has also been argued that bronchial thermoplasty may have modulating effects on neuroendocrine epithelial cells, bronchial nerve endings, TRPV1 nerve receptors, and type- $\mathrm{C}$ unmyelinated fibers in the bronchial mucosa. This may involve interrupting the central and local reflexes responsible for the activation of bronchospasm in the presence of bronchial hyperreactivity. Several questions remain regarding the use of bronchial thermoplasty, mechanism of action, selection of appropriate patients, and long-term effects. In this review, the role of ASM in the pathogenesis of asthma and the key aspects of bronchial thermoplasty are discussed, with a focus on the potential clinical effects of this promising procedure, beyond the reduction in ASM.
\end{abstract}

Keywords: airway, nerve, receptors, asthma, inflammation

\section{Introduction}

Recently, there have been studies on the role of hypersensitivity and inflammation in asthma, but the role of bronchial smooth muscle remains unclear. In the last decade, increasing knowledge of the pathophysiology and pathogenesis of asthma has led to the development of new pharmacological and non-pharmacological treatments for asthma. New therapeutic approaches have been focused on individual clinical phenotypes and to meet the needs of patients with uncontrolled asthma and poor quality of life. However, the use of systemic steroids for the treatment of asthma has side effects, with a significant impact on health care resources.

In the past decade, new therapeutic approaches for asthma have included the use of biological agents, such as omalizumab, a recombinant DNA-derived humanized monoclonal antibody to $\mathrm{IgE}{ }^{1}$ However, the newer monoclonal antibody therapies for asthma have a limited range of application to specific subgroups of patients with severe uncontrolled IgE-mediated allergic asthma. ${ }^{1}$ In this context, the use of anti-IgE
Correspondence: Francesco Menzella Department of Medical Specialties, Pneumology Unit, IRCCS Arcispedale Santa Maria Nuova, Viale Risorgimento 56, 42123 Reggio Emilia, Italy

Tel +39522 296073

Fax +39522 296182

Email menzella.francesco@ausl.re.it
Therapeutics and Clinical Risk Management 2017:13 I213-1221

1213

Dovepress f in 0

http://dx,doi.org/40.2147/TTCRM.S144604 (c) (1) (2) 2017 Menzella et al. This work is published and licensed by Dove Medical Press Limited. The full terms of this license are available at https://www.dovepres.com/terms.php cc) and incorporate the Creative Commons Attribution - Non Commercial (unported, v3.0) License (http://creativecommons.org//icenses/by-nd/3.0/). By accessing the work you hereby accept the Terms. Non-commercial uses of the work are permitted without any further permission from Dove Medical Press Limited, provided the work is properly attributed. For permission for commercial use of this work, please see paragraphs 4.2 and 5 of our Terms (https://www.dovepress.com/terms.php). 
monoclonal antibodies has been very effective and has made it possible to improve the quality of life for some patients with asthma. ${ }^{1}$ However, patients with severe asthma and no indication for or response to omalizumab have had to wait for alternative treatments, such as the new targeted antiIL-5 monoclonal antibodies including mepolizumab and reslizumab, recently approved for the treatment of severe refractory asthma. ${ }^{2,3}$

A new non-pharmacological treatment option for asthma is bronchial thermoplasty, which is performed by bronchoscopy. Bronchial thermoplasty is an endoscopic procedure that was approved by the US Food and Drug Administration (FDA) in 2010 for the treatment of severe refractory asthma, based on the local delivery of radio frequency at $65^{\circ} \mathrm{C}$ to the airways, with the aim of controlling bronchospasm through a reduction in airway smooth muscle (ASM). However, the large-scale use of bronchial thermoplasty has not been widely accepted, and there remains some controversy regarding its use.

In this review, the role of ASM in the pathogenesis of asthma is discussed along with the key aspects of bronchial thermoplasty, especially its original mechanism of action and the correct criteria for patient selection, with a special focus on the effects of this promising procedure on aspects that go beyond the mere reduction of ASM as the main determinant of clinical results. We also try to give insights on the possible place of bronchial thermoplasty in the context of a therapeutic plan for severe asthma.

\section{The role of ASM}

Histology of lung tissue shows that asthma is characterized by chronic inflammation, with bronchial epithelial basal membrane thickening, epithelial desquamation, increased vascularization, smooth muscle hypertrophy and hyperplasia, and mucous gland hypertrophy. The role of ASM is still unclear, not only in bronchial asthma but also in healthy subjects. ASM cells in asthma patients proliferate more rapidly than in nonasthmatic patients, resulting in an increase in smooth muscle mass, with airway narrowing and loss of respiratory function. ${ }^{4}$ Aubier et al showed an increase in ASM mass due to aberrant expression and activation of PAR2-mediated pathway in young patients with severe asthma. ${ }^{5}$ There is agreement that bronchial remodeling is a consequence of chronic inflammation and that this has a major role in the pathogenesis and clinical progression of asthma. ${ }^{6,7}$ The interaction between damaged epithelial cells and undifferentiated mesenchymal cells mediated by pro-inflammatory cytokines is believed to be important in the pathogenesis of asthma. ${ }^{6,7}$ As a result, the proliferation and differentiation of mesenchymal cells to myofibroblasts increases the deposition of extracellular matrix (ECM) and smooth muscle cells. ${ }^{6,7}$

Carroll et al have highlighted the role of increased production of collagen and increased myofibroblasts, grouped in longitudinal bundles, in proximal and peripheral airways of patients with fatal asthma. ${ }^{8}$ All of the above modifications, in particular, ASM and ECM deposition, increase the airway wall thickness, which correlates with severity and duration of clinical episodes of asthma. ${ }^{9}$

In 2008, a report by the National Heart, Lung, and Blood Institute (NHLBI) indicated that ASM remodeling and seven other structural changes associated with asthma may begin with the discontinuation of the normal development of the bronchial tree after exposure to allergens and other noxious agents during intrauterine and neonatal life, when the lungs are in active growth and differentiation. ${ }^{10}$ The NHLBI also proposed that ASM may acquire a regulatory pacemaker function of bronchial contractility through a neural stimulus and induce inflammation through cytokine production. ${ }^{10}$ These new data may help researchers to explain ASM contractility through a hierarchy of proximal airway pacemakers comparable to those already demonstrated in the developing lung. ${ }^{11}$

Bronchial remodeling, in particular an increase in ASM, is closely related to airway hyperresponsiveness (AHR), which is a typical feature of asthma, which has been demonstrated since the early studies on asthma in humans. ${ }^{12}$ Pepe et al demonstrated an increase in ASM and expression of IL-8 and eotaxin (a CC chemokine subfamily of eosinophil chemotactic proteins) in patients with severe asthma compared with subjects with moderate asthma. ${ }^{13}$ These published findings led to the conclusion that smooth muscle cell alteration is the fundamental structural change that distinguishes severe from moderate asthma, and that phenotypic changes in ASM could contribute to reducing control in subjects with severe asthma. ${ }^{10}$ There have also been in vitro studies on animal models where two types of ASM have been shown: the first is hyperreactive ASM characterized by the expression of markers such as alpha smooth muscle actin and an increased contractile response to external stimuli; the second is secretory ASM that is able to produce cytokines. These ASM phenotypes can coexist, and "switching" also occurs between phenotypes.

\section{Bronchial thermoplasty}

Bronchial thermoplasty is an endoscopic procedure, approved by the FDA in 2010, for the treatment of severe refractory asthma. ${ }^{14}$ The technique of bronchial thermoplasty is based on 
the endobronchial controlled delivery of thermal energy, with the aim to modify the structure of the airway wall essentially reducing the amount of smooth muscle with a device called the Alair Bronchial Thermoplasty System (Boston Scientific, Marlborough, MA, USA). A fibrobronchoscope accommodates a disposable catheter with a diameter of $2.0 \mathrm{~mm}$ in the operating channel, to obtain better visualization and complete treatment of subsegmental bronchi. ${ }^{15}$ The distal tip contains an expandable four-electrode basket, through which $65^{\circ} \mathrm{C}$ radio frequencies are delivered in order to treat all visible bronchial areas serially. ${ }^{15}$ The sequence of radiofrequency treatment is the lower right lobe, lower left lobe, and upper lobes. ${ }^{15}$ By convention, the middle lobe is not treated due to the possible risk of bronchial stenosis because of its small diameter. ${ }^{15}$ Bronchial thermoplasty is completed after three procedures performed at 20-day intervals. Several clinical trials have demonstrated the long-term safety and effectiveness of bronchial thermoplasty in terms of reducing exacerbations of asthma and improving patient quality of life, but the implications of the use of bronchial thermoplasty on health care costs remain controversial. ${ }^{16,17}$

On the basis of current knowledge, the assumption is that bronchial thermoplasty can denature and destroy ASM allowing the reduction of bronchospasm, resulting in improved control of the symptoms of severe asthma. Early feasibility studies in canine animal models have demonstrated that bronchial thermoplasty causes almost complete destruction of smooth muscle cells with moderate connective tissue deposition when lung tissue has been examined histologically. ${ }^{18}$ In the same study, it was demonstrated that bronchospasm induced in dogs using stimulation with methacholine instilled by bronchoscopy (a bronchial challenge test) did not occur in bronchi treated with bronchial thermoplasty. ${ }^{18}$ Dyrda et al studied the effects of applying various in vitro heat gradients to bovine ASM. ${ }^{19}$ Temperatures greater than $55^{\circ} \mathrm{C}$, as used in bronchial thermoplasty, caused direct destruction of actin-myosin complexes, probably due to protein denaturation with immediate loss of ASM functionality. ${ }^{19}$ Histological preparations have also demonstrated a lack of necrosis or apoptosis, and studies conducted on healthy subjects treated with bronchial thermoplasty confirmed the destruction of ASM. ${ }^{20}$

\section{Efficacy data in the short and long term: from trials to real life}

The first randomized clinical trial (RCT) evaluating the efficacy of bronchial thermoplasty was conducted in 2006 by Cox et al on 16 patients with stable mild-to-moderate asthma. ${ }^{21}$ The purpose of the study was to evaluate the safety and impact of the procedure, which was well tolerated with only mild adverse events that resolved spontaneously or when current medications were increased. ${ }^{21}$ Although not the main objective of the study, there was a significant reduction in AHR, confirmed two years following the procedure, determined by the provocative concentrations of methacholine required to induce a fall in forced expiratory volume in one second $\left(\mathrm{FEV}_{1}\right)$ of $20 \%$ or more (PC20) that was $0.92 \mathrm{mg} / \mathrm{mL}$ at baseline and $3.40 \mathrm{mg} / \mathrm{mL}$ at two years. ${ }^{21}$ The study also showed an improvement in peak expiratory flow (PEF) rates and an increase in symptom-free days (47\% vs $73 \%)(P=0.015)$, but there were no changes in $\mathrm{FEV}_{1}$ or parenchymal alterations on chest computed tomogram (CT) observed during the two-year follow-up. ${ }^{21}$

In 2007, the Asthma Intervention Research (AIR) trial was published, which was an RCT that included 112 patients with moderate-to-severe asthma $\left(\mathrm{FEV}_{1}\right.$ between $60 \%$ and $85 \%$ of predicted, and a positive methacholine test) treated with bronchial thermoplasty. ${ }^{22}$ There were no changes in the prebronchodilator $\mathrm{FEV}_{1}$ and bronchial hyperreactivity among patients undergoing bronchial thermoplasty when compared with the control group, but there was a significant improvement in terms of asthma symptoms, symptom-free days, and patient quality of life scores determined using the Asthma Quality of Life Questionnaire (AQLQ) (1.3\% $\pm 1.0 \%$ vs $0.6 \% \pm 1.0 \%, P=0.005)$, and Asthma Control Questionnaire (ACQ) score $(1.3 \pm 1.0$ vs $0.6 \pm 1.1, P=0.003) .{ }^{22}$ The results of the AIR trial also showed a significant reduction in mild exacerbations of asthma, with a fall of $0.16 \pm 0.37$ vs $0.04 \pm 0.29$ asthma attacks per subject per week $(P=0.005)$ and an increase in the morning PEF, in patients with asthma undergoing bronchial thermoplasty. ${ }^{22}$

Also in 2007, the findings of the Research in Severe Asthma (RISA) trial on the safety and efficacy of bronchial thermoplasty in symptomatic, severe uncontrolled asthma were published. ${ }^{23}$ This study enrolled 32 patients, $50 \%$ on oral corticosteroids (OCSs) with a daily dose of 15-20 mg/day of prednisone, of whom 15 patients were randomized to bronchial thermoplasty. ${ }^{23}$ Patients undergoing bronchial thermoplasty showed a significant improvement in prebronchodilator $\mathrm{FEV}_{1}$, which then returned to baseline levels after OCS tapering. ${ }^{23}$ Improvements determined by the use of the ACQ and AQLQ persisted despite the reduction of OCSs and bronchodilators, but this study was not blinded, so a placebo effect cannot be excluded on the benefits found in patients undergoing bronchial thermoplasty. ${ }^{23}$ To overcome this study limitation, AIR-2, a randomized, doubleblind, sham-controlled, multicenter trial, was designed. ${ }^{24}$ In the AIR-2 trial, 288 patients with severe asthma treated 
with high doses of inhaled corticosteroids and a long-acting beta-agonist were enrolled, of whom 190 underwent bronchial thermoplasty. ${ }^{23}$ The main goal of the RISA trial was to increase the AQLQ score vs baseline: patients treated with bronchial thermoplasty compared with those undergoing sham bronchoscopy showed a significant increase of at least 0.5 points in $79 \%$ of cases compared with $64 \% .^{23}$ There was also a reduction in number of exacerbations of asthma (32\%), visits to emergency department (84\%), and lost working days (66\%), with a small placebo effect in the study control arm. ${ }^{23}$

These controlled clinical studies demonstrated the effectiveness of bronchial thermoplasty on clinical outcomes, particularly the reduction of exacerbations of asthma, and supported the approval of the use of bronchial thermoplasty by the FDA in 2010 (Table 1). However, there are still limited data on the long-term safety of bronchial thermoplasty, especially because of early concerns about thermal damage, including bronchial stenosis, and bronchomalacia, which remain to be investigated.

In an attempt to address the long-term safety issues associated with the use of bronchial thermoplasty, a group of patients enrolled in the AIR, RISA, and AIR-2 trials were included in a long-term follow-up study. ${ }^{23-25}$ In this safety study, 45 patients undergoing bronchial thermoplasty were followed for a total of five years, while control patients were followed for a total of three years. ${ }^{25}$ Compared with the control group, patients undergoing bronchial thermoplasty had similar rates of clinical exacerbations of asthma, courses of treatment with OCSs, hospitalizations, and emergency visits. ${ }^{25}$
An additional finding was the significant reduction in airway hyperreactivity for up to three years with the stability of FEV values and the absence of overt radiological alterations such as pulmonary opacities or atelectasis. ${ }^{25} \mathrm{~A}$ long-term evaluation of the patients with bronchial thermoplasty included in the RISA study, 14 out of 15 at enrollment, was performed for a total of five years, which showed a significant reduction in emergency visits and hospitalizations for an exacerbation of asthma, and no deterioration of $\mathrm{FEV}_{1}{ }^{26}$

Similar long-term observations have also been made for the AIR-2 study in which patients were also monitored to evaluate the long-term effects of bronchial thermoplasty. ${ }^{27}$ Of the initial 192 patients enrolled in AIR-2, 160 patients were followed for other four years, and patients treated with bronchial thermoplasty showed a persistent reduction of severe exacerbations of asthma and emergency hospital visits. ${ }^{27}$ However, this study did have the limitation that control patients undergoing sham bronchoscopy were not followed up in the same way as patients treated with bronchial thermoplasty. ${ }^{27}$ Therefore, long-term comparative safety studies for the use of bronchial thermoplasty in the treatment of asthma are still recommended.

From review of the published literature on the use of bronchial thermoplasty for the treatment of asthma, there remain questions and controversies arising from the type of patient populations studied, and the definitions and inclusion of comparative control patient groups, and there are some remaining practical questions regarding the bronchial thermoplasty technique. ${ }^{28}$ First of all, bronchial thermoplasty does not reach the small peripheral airways, which is an

Table I History of bronchial thermoplasty: major studies since 2006

\begin{tabular}{|c|c|c|c|}
\hline Study & Study population & Study design & Results \\
\hline Cox et $\mathrm{al}^{21}$ & $\begin{array}{l}16 \text { patients with mild-to- } \\
\text { moderate stable asthma }\end{array}$ & $\begin{array}{l}\text { Non-randomized, } \\
\text { prospective study }\end{array}$ & $\begin{array}{l}\text { Significant reduction in airway hyperresponsiveness and } \\
\text { increase of symptoms-free days. No changes in FEV, }\end{array}$ \\
\hline Cox et $\mathrm{al}^{22}$ & $\begin{array}{l}\text { I } 12 \text { patients with } \\
\text { moderate-to-severe } \\
\text { asthma }\end{array}$ & $\begin{array}{l}\text { Randomized, controlled } \\
\text { trial }\end{array}$ & $\begin{array}{l}\text { Improvements of asthma symptoms, symptom-free days, and } \\
\text { AQLQ and ACQ scores, and reduction in mild exacerbations. } \\
\text { No changes in FEV, and bronchial hyperreactivity }\end{array}$ \\
\hline Pavord et $\mathrm{al}^{23}$ & $\begin{array}{l}32 \text { patients with severe } \\
\text { uncontrolled asthma }\end{array}$ & $\begin{array}{l}\text { Randomized, double- } \\
\text { blind, parallel-group trial }\end{array}$ & $\begin{array}{l}\text { Significant improvement in } \mathrm{FEV} \text {, and } \mathrm{ACQ} \text { scores. Limitation: } \\
\text { effective placebo }\end{array}$ \\
\hline Castro et $\mathrm{al}^{24}$ & $\begin{array}{l}288 \text { patients with severe, } \\
\text { uncontrolled asthma }\end{array}$ & $\begin{array}{l}\text { Randomized, double- } \\
\text { blind, controlled, } \\
\text { multicenter-based trial }\end{array}$ & $\begin{array}{l}\text { Increase of AQLQ score, and reduction of rate of } \\
\text { exacerbations, emergency hospital visits, and lost } \\
\text { working days }\end{array}$ \\
\hline Thomson et $\mathrm{al}^{25}$ & $\begin{array}{l}69 \text { patients enrolled in } \\
\text { the AIR trial }\end{array}$ & $\begin{array}{l}\text { Long-term follow-up } \\
\text { study }\end{array}$ & $\begin{array}{l}\text { Significant reduction in airway hyperreactivity and stability } \\
\text { of } \mathrm{FEV}_{1} \text {. No radiological changes }\end{array}$ \\
\hline Pavord et $\mathrm{al}^{26}$ & $\begin{array}{l}\text { I patients enrolled in } \\
\text { RISA trial }\end{array}$ & $\begin{array}{l}\text { Long-term follow-up } \\
\text { study }\end{array}$ & $\begin{array}{l}\text { Significant decrease of emergency hospital admissions. } \\
\text { No changes of FEV, value }\end{array}$ \\
\hline Wechsler et $\mathrm{al}^{27}$ & $\begin{array}{l}\text { I } 60 \text { patients enrolled in } \\
\text { AIR-2 trial }\end{array}$ & $\begin{array}{l}\text { Long-term follow-up } \\
\text { study }\end{array}$ & Significant decrease of emergency hospital admissions \\
\hline
\end{tabular}

Abbreviations: FEV , forced expiratory volume in one second; AQLQ, Asthma Quality of Life Questionnaire; ACQ, Asthma Control Questionnaire; AIR, Asthma Intervention Research; RISA, Research in Severe Asthma. 
important consideration for the pathogenesis of asthma and other airway disorders. The AIR-2 study excluded patients on OCSs and those with frequent exacerbations, defined as three or more hospitalizations or with four or more OCS pulses in the previous year. ${ }^{23-25}$ Also, in the AIR-2 study, the AQLQ score difference of 0.19 between the two groups did not achieve statistical significance..$^{23-25}$ The biggest criticism of the controlled clinical studies on the use of bronchial thermoplasty has been the lack of information on the results of the sham-controlled arm, absent in early controlled trials and present only in the AIR-2 study, but never evaluated in the long term. ${ }^{23-25}$

\section{Remaining questions regarding the use of bronchial thermoplasty for patients with asthma}

Despite good clinical results in controlled studies using bronchial thermoplasty for the treatment of asthma, questions remain on the mechanism of action of this procedure. ${ }^{23-28}$ First of all, bronchial thermoplasty is applied to large bronchi, while asthma is known to be a disease of small airways where the highest concentration of ASM is found..$^{29,30}$ There is a strong interconnection of nerve fibers at this level with the cholinergic system being responsible for the regulation of the bronchomotor tone. ${ }^{29,30}$ The peripheral cholinergic nerve anatomy of the large bronchi, their interconnection with ASM, and their functional role in asthma are still poorly understood. ${ }^{29,30}$ Neurophysiology studies have shown that in large- and medium-sized bronchi, there are a large number of the TRPV1 receptors that play an important role in the cough mechanism in subjects with AHR. ${ }^{29,30}$ Stimulation of the bronchial mucosa activates the TRPV1 receptors on the terminations of the afferent type-C unmyelinated nerve fibers, and other molecules, such as the nerve growth factor, may induce activation and receptor translocation. ${ }^{29,30}$ Activation of TRPV1, via $\mathrm{Ca}^{2+}$ release, results in two afferent responses, a central reflex that causes cough, bronchoconstriction, bronchial hypersecretion, apnea, tachycardia, and hypotension and a local reflex that induces bronchoconstriction, hypersecretion, neurogenic inflammation, mast cell degranulation, polymorphonuclear leukocyte and eosinophil chemotaxis, and finally release of neuropeptides. ${ }^{31}$

Some TRPV1 receptors and type-C unmyelinated fibers are distributed in the large bronchi and are heat-sensitive. ${ }^{32}$ Recently, a study demonstrated the distribution of unmyelinated nerve fibers in the human bronchial mucosa and their potential relationships with chronic cough. ${ }^{33}$ Innervation of the submucosa extending to the epithelium and lamina propria, ASM, and mucous glands has been demonstrated. ${ }^{33}$ It is possible that bronchial thermoplasty, which destroys ASM, also involves nerve fibers interrupting central and local reflexes involved in these neural mechanisms, which would explain why bronchial thermoplasty has a positive effect on the control of symptoms or asthma, even though it is applied at the proximal level in the main bronchi.

This proposed hypothesis for the mechanism of action of bronchial thermoplasty in asthma needs to be confirmed and has been the recent subject of research conducted by our group, focusing on the action of bronchial thermoplasty on chemoreceptors and nerve $\mathrm{C}$-fibers in patients with severe asthma. ${ }^{34} \mathrm{~A}$ recent paper by Pretolani et al ${ }^{35}$ involving 15 patients with severe uncontrolled asthma has confirmed the clinical efficacy of bronchial thermoplasty, with the median values before and after bronchial thermoplasty, respectively, as follows: reduction in ASM area, $19.7 \% \pm 5.3 \%$, $(P<0.001)$; reduction in subepithelial basement membrane thickening, $4.4 \pm 3.9 \mu \mathrm{m}(P<0.02)$; reduction in submucosal nerves $(1.0 \% \pm 0.7 \%-1.3 \%)$ and ASM-associated nerves (452.6 $\pm 96.0-811.2)$ and immunoreactive pixels per $\mathrm{mm}^{2}$, $62.7 \pm 0-230.3$; and reduction in neuroendocrine epithelial cells (NECs) per $\mathrm{mm}^{2}, 4.9 \pm 0.0(P<0.02) .{ }^{35}$ The main novel finding of this study is the effect of bronchial thermoplasty on structural abnormalities involved in airway narrowing and bronchial reactivity, particularly ASM, NECs, and bronchial nerve endings. ${ }^{35}$

The study by Pretolani et $\mathrm{al}^{35}$ follows a study by West et al, ${ }^{36}$ who demonstrated that in patients with asthma and chronic cough, a rich non-myelinated (PGP 9.5 immunopositive) and myelinated (PGP 9.5 immunonegative) innervation in all layers of the bronchial mucosa was present. ${ }^{36}$ This study was the first to describe the potential vagal afferents responsible for cough in human airways. ${ }^{36}$ Despite the clear functional separation, reliable markers to distinguish between afferent and efferent innervation have not yet been found in human lung tissue. However, recent studies on bronchial innervation in animal models may help to direct future translational studies on airway innervation in humans. ${ }^{37-39}$

Few studies have evaluated the effects of bronchial thermoplasty on bronchial inflammation. In a study by Denner et al using bronchoalveolar lavage (BAL), there was a reduction in the expression of T-cells and RANTES or CCL5 at three and six months after bronchial thermoplasty in all the 11 patients on treatment. ${ }^{39}$ TRAIL cytokines were found to be increased following bronchial thermoplasty. ${ }^{39}$ The authors concluded that there were significant changes in inflammation following bronchial thermoplasty. ${ }^{39}$ However, there are many 
remaining questions that still need to be addressed, including why all asthmatic patients do not respond to bronchial thermoplasty treatment. Doeing et al published a case report in which a patient who was unresponsive to bronchial thermoplasty, demonstrated no reduction of ASM on histology of bronchial biopsies taken before and after the procedure, but showed smooth muscle hypertrophy that was comparable to the pretreatment biopsy. ${ }^{40}$

Pretolani et al showed that among a group of ten patients with asthma, three did not show any reduction in ASM after bronchial thermoplasty. ${ }^{41}$ The reasons for this finding could be related to the variation in smooth muscle cell phenotypes, as previously described, which might react differently to heat application and have a different response to therapy. ${ }^{41}$ Another study on a small series of 17 patients demonstrated that bronchial thermoplasty not only improved asthma control and reduced the smooth muscle mass of treated airway segments, regardless of baseline level of muscle mass, but also altered the deposition of collagen. ${ }^{42}$ A possible role of this treatment in bronchial remodeling is one of the topics of study currently underway, with the findings of these future studies possibly leading to either a change in the patients selected for treatment or new treatment approaches. ${ }^{43}$ A recent study that has included 300 bronchial biopsy specimens collected from 15 patients with severe uncontrolled asthma before and three months after bronchial thermoplasty showed that the procedure significantly improved asthma control and quality of life at 12 months and reduced the number of severe exacerbations and the dose of OCSs. ${ }^{35}$ At three months, the clinical benefit was associated with a reduction in ASM area, subepithelial basement membrane thickening, submucosal nerves, and ASM-associated nerves. ${ }^{35}$

In a retrospective clinical review of 15 consecutive patients with severe asthma, a statistically and clinically significant reduction was found in blood eosinophil counts after bronchial thermoplasty treatment, which had never been detected in previous studies. ${ }^{44}$ This finding would suggest that bronchial thermoplasty has an anti-inflammatory effect. ${ }^{44}$ In another case study, the authors have described a reduction in BAL fluid eosinophil counts and cytokine levels up to six weeks after bronchial thermoplasty. ${ }^{39}$ However, in this case, these findings may have been affected by OCSs administered before the procedure. ${ }^{39}$

A recent study by Debray et al reports the CT results of 13 patients undergoing bronchial thermoplasty. ${ }^{45}$ The day after treatment, patients had peribronchial thickening and pulmonary ground-glass opacities in the absence of symptoms. ${ }^{45}$ Pleural effusion and airway thickening was evident in 68\% and $39 \%$ of cases, respectively. ${ }^{45}$ The authors hypothesized that such alterations reflected alveolar inflammation and edema secondary to bronchial thermoplasty-induced heat damage, which reaches the small airways and pulmonary parenchyma. ${ }^{45}$ Such alterations might contribute to the improvement of asthma control in patients undergoing bronchial thermoplasty.

\section{Selection of the appropriate patient for treatment with bronchial thermoplasty}

For the use of bronchial thermoplasty in the management of asthma, the need to identify patient phenotypes or responsepredictive biomarkers is as important as for any other therapy. However, at this time, bronchial thermoplasty has been proven to improve the quality of life of most patients who are treated with this method, and is fully justified and approved as a valid therapeutic option for severe asthma that is uncontrolled with standard medical treatment.

However, the criterion for selection of the most appropriate patients with asthmas who are most likely to benefit from bronchial thermoplasty is still unknown. Based on the currently available treatments, selection of patients with $\mathrm{FEV}_{1} \geq 60 \%$ is predicted to be unsuitable for the currently available biologicals, including omalizumab or mepolizumab, with a lack of patient response and an unwillingness by patients to undergo therapies with an indefinite duration. The advantage of bronchial thermoplasty is that it consists of only three procedures (Table 2). However, there have

Table 2 Patient selection criteria for the use of bronchial thermoplasty

\begin{tabular}{ll}
\hline Inclusion criteria & Exclusion criteria \\
\hline $\begin{array}{l}\text { Adults with diagnosis of asthma for } \\
\text { more than } 24 \text { months according }\end{array}$ & $\begin{array}{l}\text { Patients with history of acute life- } \\
\text { threatening asthma exacerbations } \\
\text { to the Global Initiative for Asthma } \\
\text { (GINA) } 2016 \text { Global Management }\end{array}$ \\
$\begin{array}{l}\text { and Prevention Guidelines }{ }^{51} \\
\text { Patients with two exacerbations }\end{array}$ & Use of beta-blocker drugs \\
within one year before bronchial & \\
thermoplasty, or on oral & \\
corticosteroids or needing & \\
hospitalization or emergency & \\
medical care & \\
Pre-bronchodilator FEV, $\geq 60 \%$ of & Pacemaker, internal defibrillator, or \\
predicted & other implanted electronic devices \\
Patients unresponsive to biological & Known sensitivity to medications \\
therapy & used for bronchoscopy, including \\
& lidocaine, atropine, and \\
Patients unwilling to undergo a & Pregnant women \\
life-long biological therapy & \\
\hline Abbreviation: & \\
\hline
\end{tabular}

Abbreviation: $\mathrm{FEV}_{1}$, forced expiratory volume in one second. 
been studies involving small patient sample sizes, such as the study by Doeing et al study on eight patients who had severe functional impairment $\left(\mathrm{FEV}_{1}\right.$ between $52 \%$ and $37 \%$ of predicted), where bronchial thermoplasty was effective in five patients. ${ }^{46}$ Bronchial thermoplasty may also be indicated in patients with frequent asthmatic exacerbations and emergency admissions to hospital, regardless of Th1 or Th2 phenotype, or respiratory function. ${ }^{47}$ Another potentially suitable subgroup for treatment with bronchial thermoplasty could include patients with severe steroid-resistant refractory asthma, ${ }^{48}$ and also patients who do not have the chance or desire to undergo indefinite treatment with biological drugs.

The current European Respiratory Society and American Thoracic Society (ERS/ATS) clinical guidelines recommend bronchial thermoplasty in adults with severe refractory asthma, despite optimal therapy, but only in the context of an institutional review board-approved independent systematic registry, or for use in a clinical study. ${ }^{48}$ Similar recommendations have been given following a recent Cochrane Database systematic review, ${ }^{49}$ which also emphasized the need for further studies on bronchial thermoplasty to determine the mechanisms of action in patients with different phenotypes of asthma and in patients with other severe respiratory impairment. In support of these recent recommendations, the Bronchial Thermoplasty Global Registry, a two-year observational study that is expected to provide new and valuable data, is currently recruiting patients. ${ }^{50,51}$

\section{Pharmacoeconomic aspects of treatment with bronchial thermoplasty}

The introduction of new treatment options for severe asthma, such as omalizumab, mepolizumab, and bronchial thermoplasty, has an impact on direct health care costs that requires analysis. ${ }^{17,52}$ Some recent studies have shown that cost increases may be partially offset by the reduction in costs incurred by the health service, in particular, due to a reduction in emergency hospital admissions for acute exacerbations of asthma, the reduction of indirect costs, and the effects of improved quality of life of patients. ${ }^{17,53}$ A study from our group, based on a population budget-impact model with a five-year prospective horizon, has shown that the increase in direct costs has been reduced by a long-term economic saving due to a reduction in emergency hospital visits and hospitalizations due to the use of bronchial thermoplasty. ${ }^{17}$ A subsequent study confirmed that bronchial thermoplasty has a $60 \%$ chance to be cost-effective when compared with omalizumab and standard therapy on the willingness-to-pay of $\$ 100,000 /$ quality-adjusted life year, ${ }^{52}$ which is a conclusion confirmed by other authors. ${ }^{53} \mathrm{~A}$ further recent study, however, came to negative conclusions about the cost-effectiveness of bronchial thermoplasty and assumed a need for a reduction in the cost of the procedure in order to make it a more costeffective treatment option. ${ }^{54}$

\section{Safety profile of treatment with bronchial thermoplasty}

Bronchial thermoplasty has been shown to have a good long-term safety profile. ${ }^{30,32}$ There have been no cases of pneumothorax, due to the procedure, or clinical complications or patient mortality due to intubation, mechanical ventilation, or cardiac arrhythmias resulting from treatment. No cases of bronchial stenosis have been reported following bronchial thermoplasty. During bronchial thermoplasty or shortly thereafter, there have been reports of a significant but transient increase in respiratory adverse events, particularly bronchospasm, upper and lower respiratory tract infection, recurrent relapsing atelectasis, ${ }^{20}$ lower respiratory tract infection, and hemoptysis, found in $84.7 \%$ of patients undergoing bronchial thermoplasty, compared with $75.5 \%$ of patients in a control bronchoscopy group. ${ }^{35,39,41-45}$ Radiologically, bronchial thermoplasty has been reported to be associated with transient ground-glass opacities that undergo spontaneous resolution without any need for treatment. . $3,39,41-45^{-45}$

\section{Conclusion}

Bronchial thermoplasty is no longer an experimental procedure for the treatment of asthma, as controlled clinical studies have supported its efficacy in the treatment of different phenotypes of severe refractory asthma. Controlled clinical studies have shown significant improvements in the most important treatment outcomes, including symptom control, reduction of severe exacerbation rate, reduction in emergency hospital admissions, improved patient quality of life, and reduction in the loss of working days or school days lost for asthma. Bronchial thermoplasty should be considered as an adjunctive treatment to the best standard of care, and is a complex procedure that should always be performed in specialized centers with experience in bronchial thermoplasty, with appropriate intensive care support to manage any possible intra-procedure or post-procedure adverse events. The increase in direct costs of bronchial thermoplasty is significant and can be a factor that limits its implementation. However, the health care costs of bronchial thermoplasty are lower than for the use of novel biologicals for severe asthma (in particular omalizumab). There are still remaining questions regarding the mechanism of action of 
bronchial thermoplasty, patient selection, and management criteria, but data exist from the literature regarding the reduction of ASM following bronchial thermoplasty.

Bronchial thermoplasty may have different mechanisms on small airways, which are important in the pathogenesis of asthma. This may overcome any objections related to the proximal application involved in the procedure. Bronchial thermoplasty may have modulating effects on NECs, bronchial nerve endings, TRPV1 nerve receptors, and the type-C unmyelinated fibers in the bronchial mucosa in patients with asthma by interrupting central and local reflexes responsible for the activation of bronchospasm in the presence of bronchial hyperreactivity. Further studies are required on the mechanism of action of bronchial thermoplasty, including phenotyping of patients and the long-term effects of this treatment approach in patients with bronchial asthma.

\section{Disclosure}

Francesco Menzella participated in contracted research and clinical trials for Novartis, Sanofi, and GlaxoSmithKline. Nicola Facciolongo served as consultant for Boston Scientific. The other authors report no conflicts of interest in this work.

\section{References}

1. Abraham I, Alhossan A, Lee CS, Kutbi H, MacDonald K. "Real-life" effectiveness studies of omalizumab in adult patients with severe allergic asthma: systematic review. Allergy. 2016;71(5):593-610.

2. Menzella F, Lusuardi M, Galeone C, Taddei S, Facciolongo N, Zucchi L. Mepolizumab for severe refractory eosinophilic asthma: evidence to date and clinical potential. Ther Adv Chronic Dis. 2016;7(6):260-277.

3. Máspero J. Reslizumab in the treatment of inadequately controlled asthma in adults and adolescents with elevated blood eosinophils: clinical trial evidence and future prospects. Ther Adv Respir Dis. 2017; 11(8):311-325.

4. Pascual RM, Peters SP. Airway remodeling contributes to the progressive loss of lung function in asthma: an overview. J Allergy Clin Immunol. 2005;116(3):477-486.

5. Aubier M, Thabut G, Hamidi F, et al. Airway smooth muscle enlargement is associated with protease-activated receptor 2/ligand overexpression in patients with difficult-to-control severe asthma. J Allergy Clin Immunol. 2016;138(3):729-739.

6. Lauzon AM, Martin JG. Airway hyperresponsiveness; smooth muscle as the principal actor. F1000Res. 2016;5.

7. Noble PB, Pascoe CD, Lan B, et al. Airway smooth muscle in asthma: linking contraction and mechanotransduction to disease pathogenesis and remodelling. Pulm Pharmacol Ther. 2014;29(2):96-107.

8. Carroll NG, Elliot J, Morton AR, James AL. The structure of large and small airways in nonfatal and fatal asthma. Am Rev Respir Dis. 1993; 147(2):405-410.

9. Nair P, Martin JG, Cockcroft DC, et al. Airway hyperresponsiveness in asthma: measurement and clinical relevance. J Allergy Clin Immunol Pract. 2017;5(3):649.e2-659.e2.

10. Panettieri RA Jr, Kotlikoff MI, Gerthoffer WT, et al; National Heart, Lung, and Blood Institute. Airway smooth muscle in bronchial tone, inflammation, and remodeling: basic knowledge to clinical relevance. Am J Respir Crit Care Med. 2008;177(3):248-252.
11. Jesudason EC. Airway smooth muscle: an architect of the lung? Thorax. 2009;64(6):541-545.

12. Chetta A, Foresi A, Del Donno M, Bertorelli G, Pesci A, Olivieri D. Airways remodeling is a distinctive feature of asthma and is related to severity of disease. Chest. 1997;111(4):852-857.

13. Pepe C, Foley S, Shannon J, et al. Differences in airway remodeling between subjects with severe and moderate asthma. J Allergy Clin Immunol. 2005;116(3):544-549.

14. US Food and Drug Administration. FDA approves new device for adults with severe and persistent asthma. 2010. Available from: https://www. accessdata.fda.gov/cdrh_docs/pdf8/p080032a.pdf. Accessed June 6, 2017.

15. Facciolongo N, Menzella F, Lusuardi M, et al. Recurrent lung atelectasis from fibrin plugs as a very early complication of bronchial thermoplasty: a case report. Multidiscip Respir Med. 2015;10(1):9.

16. Trivedi A, Pavord ID, Castro M. Bronchial thermoplasty and biological therapy as targeted treatments for severe uncontrolled asthma. Lancet Respir Med. 2016;4(7):585-592.

17. Menzella F, Zucchi L, Piro R, Galeone C, Castagnetti C, Facciolongo N. A budget impact analysis of bronchial thermoplasty for severe asthma in clinical practice. Adv Ther. 2014;31(7):751-761.

18. Danek CJ, Lombard CM, Dungworth DL, et al. Reduction in airway hyperresponsiveness to methacholine by the application of RF energy in dogs. J Appl Physiol (1985). 2004;97(5):1946-1953.

19. Dyrda P, Tazzeo T, DoHarris L, et al. Acute response of airway muscle to extreme temperature includes disruption of actin-myosin interaction. Am J Respir Cell Mol Biol. 2011;44(2):213-221.

20. Miller JD, Cox G, Vincic L, Lombard CM, Loomas BE, Danek CJ. A prospective feasibility study of bronchial thermoplasty in the human airway. Chest. 2005;127(6):1999-2006.

21. Cox G, Miller JD, McWilliams A, Fitzgerald JM, Lam S. Bronchial thermoplasty for asthma. Am J Respir Crit Care Med. 2006;173(9): 965-969.

22. Cox G, Thomson NC, Rubin AS, et al; AIR Trial Study Group. Asthma control during the year after bronchial thermoplasty. $N$ Engl J Med. 2007;356(13):1327-1337.

23. Pavord ID, Cox G, Thomson NC, et al; RISA Trial Study Group. Safety and efficacy of bronchial thermoplasty in symptomatic, severe asthma. Am J Respir Crit Care Med. 2007;176(12):1185-1191.

24. Castro M, Rubin AS, Laviolette M, et al; AIR2 Trial Study Group. Effectiveness and safety of bronchial thermoplasty in the treatment of severe asthma: a multicenter, randomized, double-blind, sham-controlled clinical trial. Am J Respir Crit Care Med. 2010;181(2):116-124.

25. Thomson NC, Rubin AS, Niven RM, et al; AIR Trial Study Group. Long-term (5 year) safety of bronchial thermoplasty: Asthma Intervention Research (AIR) trial. BMC Pulm Med. 2011;11:8.

26. Pavord ID, Thomson NC, Niven RM, et al; Research in Severe Asthma Trial Study Group. Safety of bronchial thermoplasty in patients with severe refractory asthma. Ann Allergy Asthma Immunol. 2013;111(5): 402-407.

27. Wechsler ME, Laviolette M, Rubin AS, et al; Asthma Intervention Research 2 Trial Study Group. Bronchial thermoplasty: long-term safety and effectiveness in patients with severe persistent asthma. J Allergy Clin Immunol. 2013;132(6):1295-1302.

28. Iyer VN, Lim KG. Bronchial thermoplasty: reappraising the evidence (or lack thereof). Chest. 2014;146(1):17-21.

29. Geppetti P, Materazzi S, Nicoletti P. The transient receptor potential vanilloid 1: role in airway inflammation and disease. Eur J Pharmacol. 2006;533(1-3):207-214.

30. Fisher JT. The TRPV1 ion channel: implications for respiratory sensation and dyspnea. Respir Physiol Neurobiol. 2009;167(1):45-52.

31. Grace MS, Baxter M, Dubuis E, Birrell MA, Belvisi MG. Transient receptor potential (TRP) channels in the airway: role in airway disease. Br J Pharmacol. 2014;171(10):2593-2607.

32. Brito R, Sheth S, Mukherjea D, Rybak LP, Ramkumar V. TRPV1: a potential drug target for treating various diseases. Cells. 2014;3(2): $517-545$. 
33. Hsu CC, Lee LY. Role of calcium ions in the positive interaction between TRPA1 and TRPV1 channels in bronchopulmonary sensory neurons. J Appl Physiol (1985). 2015;118(12):1533-1543.

34. Facciolongo N, Di Stefano A, Pietrini V, et al. The effect of bronchial thermoplasty on nerve $\mathrm{C}$-fibers and inflammatory cells in patients with severe asthma. Eur Respir J. 2015;46:59.

35. Pretolani M, Bergqvist A, Thabut G, et al. Effectiveness of bronchial thermoplasty in patients with severe refractory asthma: clinical and histopathologic correlations. J Allergy Clin Immunol. 2017;139(4) 1176-1185.

36. West PW, Canning BJ, Merlo-Pich E, Woodcock AA, Smith JA. Morphologic characterization of nerves in whole-mount airway biopsies. Am J Respir Crit Care Med. 2015;192(1):30-39.

37. Henderson WR Jr, Chi EY, Maliszewski CR. Soluble IL-4 receptor inhibits airway inflammation following allergen challenge in a mouse model of asthma. J Immunol. 2000;164(2):1086-1095.

38. Tomkinson A, Duez C, Cieslewicz G, et al. A murine IL-4 receptor antagonist that inhibits IL-4- and IL-13-induced responses prevents antigen-induced airway eosinophilia and airway hyperresponsiveness. J Immunol. 2001;166(9):5792-5800.

39. Denner DR, Doeing DC, Hogarth DK, Dugan K, Naureckas ET, White SR. Airway inflammation after bronchial thermoplasty for severe asthma. Ann Am Thorac Soc. 2015;12(9):1302-1309.

40. Doeing DC, Husain AN, Naureckas ET, White SR, Hogarth DK. Bronchial thermoplasty failure in severe persistent asthma: a case report. J Asthma. 2013;50(7):799-801.

41. Pretolani M, Dombret MC, Thabut G, et al. Reduction of airway smooth muscle mass by bronchial thermoplasty in patients with severe asthma. Am J Respir Crit Care Med. 2014;190(12):1452-1454.

42. Chakir J, Haj-Salem I, Gras D, et al. Effects of bronchial thermoplasty on airway smooth muscle and collagen deposition in asthma. Ann Am Thorac Soc. 2015;12(11):1612-1618.

43. University of Leicester (UK). Bronchial thermoplasty study: an observational study examining airway remodelling and repair in patients with severe persistent asthma treated with bronchial thermoplasty. 2014. Available from: http://www.isrctn.com/ISRCTN94263922. NLM identifier: ISRCTN94263922. Accessed April 30, 2017.
44. Ryan DM, Fowler SJ, Niven RM. Reduction in peripheral blood eosinophil counts after bronchial thermoplasty. J Allergy Clin Immunol. 2016;138(1):308-310.

45. Debray MP, Dombret MC, Pretolani M, et al. Early computed tomography modifications following bronchial thermoplasty in patients with severe asthma. Eur Respir J. 2017;49(3):1601565.

46. Doeing DC, Mahajan AK, White SR, Naureckas ET, Krishnan JA, Hogarth DK. Safety and feasibility of bronchial thermoplasty in asthma patients with very severe fixed airflow obstruction: a case series J Asthma. 2013;50(2):215-218.

47. Fajt ML, Wenzel SE. Development of new therapies for severe asthma. Allergy Asthma Immunol Res. 2017;9(1):3-14.

48. Wenzel SE. Asthma phenotypes: the evolution from clinical to molecular approaches. Nat Med. 2012;18(5):716-725.

49. Torrego A, Solà I, Munoz AM, et al. Bronchial thermoplasty for moderate or severe persistent asthma in adults. Cochrane Database Syst Rev. 2014;(3):CD009910.

50. Boston Scientific. Bronchial Thermoplasty Global Registry (BT Registry). 2014. Available from: https://clinicaltrials.gov/ct2/show/ NCT02104856. ClinicalTrials.gov identifier: NCT02104856. Accessed April 30, 2017.

51. Global Initiative for Asthma (GINA) 2016 Global Management and Prevention Guidelines. Available from: http://ginasthma.org/wp-content/uploads/2016/04/GINA-2016-main-report_tracked.pdf. Accessed April 30, 2017.

52. Zafari Z, Sadatsafavi M, Marra CA, Chen W, FitzGerald JM. Costeffectiveness of bronchial thermoplasty, omalizumab, and standard therapy for moderate-to-severe allergic asthma. PLoS One. 2016;11(1): e0146003

53. Cangelosi MJ, Ortendahl JD, Meckley LM, et al. Cost-effectiveness of bronchial thermoplasty in commercially-insured patients with poorly controlled, severe, persistent asthma. Expert Rev Pharmacoecon Outcomes Res. 2015;15(2):357-364.

54. Nguyen HV, Bose S, Mital S, et al. Is bronchial thermoplasty cost-effective as treatment for problematic asthma patients? Singapore's perspective on a global model. Respirology. 2017;22(6) 1102-1109.
Therapeutics and Clinical Risk Management

\section{Publish your work in this journal}

Therapeutics and Clinical Risk Management is an international, peerreviewed journal of clinical therapeutics and risk management, focusing on concise rapid reporting of clinical studies in all therapeutic areas, outcomes, safety, and programs for the effective, safe, and sustained use of medicines. This journal is indexed on PubMed Central, CAS,

\section{Dovepress}

EMBase, Scopus and the Elsevier Bibliographic databases. The manuscript management system is completely online and includes a very quick and fair peer-review system, which is all easy to use. Visit http://www.dovepress.com/testimonials.php to read real quotes from published authors. 